\title{
Prevalence of Cancer Patients Requiring Palliative Care in Outpatient Clinics in a Tertiary Hospital in Southern Thailand
}

\author{
Orapan Fumaneeshoat, M.D. ${ }^{1}$, Thammasin Ingviya, M.D., Ph.D. ${ }^{1,2,3,4}$, Supakorn Sripaew, M.D. ${ }^{1}$ \\ 'Department of Family and Preventive Medicine, Faculty of Medicine, Prince of Songkla University, Hat Yai, Songkhla 90110, Thailand. \\ ${ }^{2}$ Medical Data Center for Research and Innovation, Faculty of Medicine, Prince of Songkla University, Hat Yai, Songkhla 90110, Thailand. \\ ${ }^{3}$ Air Pollution and Health Effect Research Center, Prince of Songkla University, Hat Yai, Songkhla 90110, Thailand. \\ ${ }^{4}$ Research Center for Cancer Control in Thailand, Faculty of Medicine, Prince of Songkla University, Hat Yai, Songkhla 90110, Thailand. \\ Received 12 July 2020 • Revised 11 October 2020 • Accepted 20 October 2020 • Published online 5 April 2021
}

\begin{abstract}
:
Objective: To estimate the prevalence of patients requiring palliative care in outpatient clinics and associated factors. Materials and Methods: A cross-sectional study was conducted by retrospectively reviewing the electronic medical records of cancer patients visiting the outpatient clinics in the major tertiary care institution in southern Thailand during 1 January31 December 2018 from the Hospital Information System. The Supportive and Palliative Care Indicators Tool in Low Income Settings (SPICT-LIS ${ }^{\mathrm{TM}}$ ) was used to determine if the patients would benefit from palliative care. Forward stepwise multiple logistic regression was used to assess associations between potential factors and the need for palliative care. Results: Nine thousand nine hundred and ninety medical records were reviewed. 3,628 (36.3\%) patients were male and $6,324(63.3 \%)$ were female with a median age of 58.7 years. The prevalence of cancer patients requiring palliative care according to the SPICT-LIS ${ }^{\mathrm{TM}}$ criteria was $7.8 \%$. Age was the main factor associated with palliative care need [odds ratio $(O R)=1.03,95 \%$ confidence interval $(C l)=1.02-1.04$ ]. Muslim patients had a significantly higher requirement for palliative care compared with Buddhist patients $(\mathrm{OR}=1.62,95 \% \mathrm{Cl}=1.09-2.37)$. Although not statistically significant, malignant neoplasms of bone and articular cartilage were associated with higher palliative care need than lip, oral cavity and pharynx cancers (OR=5.35, 95\% Cl=0.69-29.40).

Conclusion: Muslim religion and having malignant neoplasms of bone and articular cartilage were associated with the highest palliative care need. Future studies should focus on more in-depth examination of the reasons these groups have higher needs for palliative care.
\end{abstract}

Keywords: cancer, outpatient, palliative care, SPICT-LIS

Contact: Thammasin Ingviya, M.D., Ph.D.

Department of Family and Preventive Medicine, Faculty of Medicine,

Prince of Songkla University, Hat Yai, Songkhla 90110, Thailand.

E-mail: Thammasin.i@psu.ac.th

. Hosting by Prince of Songkla University. All rights reserved.

This is an open access article under the CC BY-NC-ND license

(http://www.jhsmr.org/index.php/jhsmr/about/editorialPolicies\#openAccessPolicy).

J Health Sci Med Res 2021;39(5):411-421 doi: 10.31584 /jhsmr.2021798 www.jhsmr.org 


\section{Introduction}

The numbers of Thai people suffering from cancer and non-cancer diseases has been increasing in the past decade (2008-2018). ${ }^{1,2}$ The age-standardized incidence rate for overall cancer in Thailand in 2018 was 158.2 per 100,000 population. ${ }^{2}$ The average annual percent changes of certain cancers including lung and breast cancer increased by $3.1 \%$ and 3.3\% from year 2000-2012 and were expected to continue increasing up to year $2025 .^{3}$ Patients with certain diseases such as Alzheimer's and dementia, liver cirrhosis, kidney diseases, pulmonary diseases and cancer have been identified as in need for palliative care. ${ }^{4}$ However, not all patients with those diseases are in need of palliative care. It depends on the psychosocial, spiritual and physical necessities of the patient rather than on the diagnosis. ${ }^{4}$ The principle of palliative care is to ascertain the way to achieve the best possible quality of life for patients with serious illness and their families by providing psychological and physical support, symptom control for severe medical problems such as pain or dyspnea and comfort care. ${ }^{4}$

Palliative care is an important aspect in improving the quality of life of patients who are diagnosed with life-limiting illnesses such as cancer, and their families. ${ }^{5}$ Palliative care can also indirectly help the hospitals in the Thai healthcare system reduce unnecessary expenditures by not needing to provide treatments which are not desired by the patients or their families. ${ }^{6-8}$ However, even in today's advanced medical systems, most patients do not access appropriate and available palliative care. The World Health Organization $(\mathrm{WHO})$ recently reported that only $14.0 \%$ of patients who would benefit from palliative care received it. ${ }^{9}$

Recently the Supportive and Palliative Care Indicators Tool-Low Income Setting (SPICT-LIS ${ }^{\mathrm{TM}}$ ) was developed, to help in identifying patients with cancer and other life-limiting diseases who could benefit from a palliative care approach to their management so that they received care appropriate to their needs and coordinated care planning. ${ }^{10}$ The SPICT-
LIS $^{\text {TM }}$ was designed to help healthcare providers determine if the patients are in an advanced stage of their illnesses. ${ }^{10}$ If the general and disease specific criteria are positive for a patient, it is suggested that the patient will benefit from a palliative care in addition to the specific disease management. ${ }^{10}$ The tool may be used as a screening tool in clinical and research settings to estimate the prevalence of patients, including those with cancer, who require palliative care.

To estimate the need for palliative care personnel and infrastructure, accurate data are required concerning the number of patients requiring both inpatient palliative care, and even more outpatient palliative care, where most cancer patients interact with the healthcare system. Theoretically, if screening to assess the need for palliative care is performed at outpatient departments, more of these patients will receive appropriate palliative care, leading to decreases in hospitalization rates in the last 6 months of their lives. ${ }^{11}$

In developed countries, tertiary hospitals have palliative care specialists who provide expert opinions benefitting patients and other specialists. ${ }^{12}$ However, in Thailand, the palliative care services are provided with limitations such as no proper consultation channels in tertiary hospitals. In addition, the prevalence of palliative care needs in cancer patients in Thailand, especially in the outpatient clinics of tertiary hospitals, is unknown. Therefore, this study was undertaken to estimate the prevalence of cancer patients requiring palliative care in outpatient clinics and assess factors associated with this need in Songklanagarind Hospital, the primary tertiary care center and referral institute in southern Thailand.

\section{Material and Methods}

This was a retrospective cross-sectional study performed by reviewing the electronic medical records of cancer patients visiting the outpatient clinics of 
Songklanagarind Hospital from 1 January-31 December 2018. Cancer patients were randomly selected from the list, based on the inclusion criteria of Thai patients aged 15 years old or older who were diagnosed based on the $10^{\text {th }}$ revision of the International Classification of Disease and Related Health Problems (ICD-10) with malignancy categories C00-C97. We excluded cancer patients visiting the emergency room or who were referred from another hospital for surgery.

The required sample size was calculated using the formula to estimate an infinite population. The type I error was assumed to be 0.05 and the type II error was assumed to be 0.2 . The margin of error was set at 0.01 . The estimated proportion of people who would need palliative care was deemed to be 0.50 following the study of Hamano et al. ${ }^{13}$ The calculated sample size needed for our analysis was then 9,604 .

For data collection, an online SPICT-LIS form was developed using KoBoToolbox software. General information of the patients including date of birth, sex, religion, health insurance and clinical data were retrieved from the Hospital Information System (HIS), along with the particular clinic visited and primary diagnosis of cancer by ICD-10. The palliative care requirement for each patient was determined based on the supportive and palliative care indicators in a low-income setting (SPICT-LIS ${ }^{\mathrm{TM}}$ ) criteria.

The primary outcome measure was the palliative care needs in the study cancer patients. If a patient had more than one visit in the year, the last visit in the study year 2018 was selected for review because we hypothesized that the latest visit would be when the patient's condition was at its lowest due to cancer progression.

The Thai version of the SPICT-LIS ${ }^{\text {TM }}$ was backtranslated from English to Thai by a palliative home care team and epidemiologists in Songklanagarind Hospital. The validity of the questionnaires was tested by comparing the back-translated version to the original version. The reliability examined by case vignettes was 0.66 by Fleiss kappa coefficient, while subgroup agreements were 0.93 among 11 doctors and 0.53 among 23 nurses. The tool was used to determine if the patient require a palliative care consultation by the palliative care services at Songklanagarind Hospital. The original SPICT-LIS was based on from the Supportive and Palliative Care Indicators Tool (SPICT), created by the Collaborative Palliative Care Team in Edinburgh in 2010. ${ }^{14}$ The SPICT-LIS was refined from preliminary testing in Nepal and consensus building by expert clinicians from Africa and Asia by adding questions on communicable diseases such as HIV and tuberculosis to the basic SPICT. ${ }^{10}$

The SPICT-LIS is divided into two parts. The first part includes 6 general indicators and the second part includes 28 clinical indicators. A patient is considered in need of palliative care when they have at least 2 general indicators and at least one clinical indicator. ${ }^{10}$ A study by Bock et al. ${ }^{15}$ found that using this definition, the SPICT-LIS had a sensitivity of $84.1 \%$ and specificity of $57.9 \%$ in predicting one-year mortality in SPICT-positive elderly patients with unpredictable prognoses who were hospitalized.

All statistical analyses were performed with $R$ Program version 3.6.1 (R Core Team, Austria). Inferential statistics including Wilcoxon rank-sum test, chi-squared test and Fisher's exact test were used to compare the characteristics of the patients who needed palliative care with those of the patients who did not. For inferential analysis, multivariate logistic regression was used to analyze the associations between patients requiring palliative care and associated factors. To select potential associated factors, backward stepwise variable selection based on the Akaike Information Criterion (AIC) was performed. A p-value less than 0.05 was considered statistically significant. 


\section{Results}

\section{Patient characteristics}

The total number of outpatients in our institution in 2018 was 227,691, with 23,568 patients diagnosed with ICD-10: C00-C97. After excluding patients under 15 years old, patients visiting the emergency department and those referred from other hospitals for surgery, the total study population was 9,990 cancer patients (Figure 1).

Of the 9,990 cancer patients included in the study, the median age was 58.7 years. 3,628 (36.3\%) were male, $6,324(63.3 \%)$ were female and 38 had no data recorded on sex $(0.4 \%)$. For insurance purposes, 3,156 of the patients were under the Civil Servant Medical Benefits Scheme (CSMBS) or the State Enterprise Scheme (31.6\%). Most of the participants were Buddhist (84.3\%). The top three primary cancers by ICD-10 definitions were 1,887 (18.9\%) malignant neoplasms of the breast (ICD-10:C50), 1,755 (17.6\%) malignant neoplasms of the digestive organs
(ICD-10:C15-26) and 1,411 (14.1\%) malignant neoplasms of the female genital organs (ICD-10:C51-58). The top three outpatient departments with the highest numbers of cancer patients were surgery $(32.3 \%)$, radiation oncology (22.4\%) and medicine (21.7\%) (Table 1).

\section{Cancer Patients requiring palliative care by} characteristics and SPICT-LIS indicators

Seven hundred eighty-one patients $(7.8 \%)$ were found to require palliative care following the SPICT-LIS minimum criteria of 2 general indicators and 1 clinical indicator, 409 males (52.4\%) and, 370 females (47.4\%), with a median age of 63 years. About one fourth (27.3\%) were under the CSMBS insurance scheme. The top three primary cancers were malignant neoplasms of the digestive organs (29.8\%), malignant neoplasms of the respiratory and intrathoracic organs (17.5\%) and malignant neoplasms of the lip, oral cavity and pharynx (10.6\%) (Table 2).

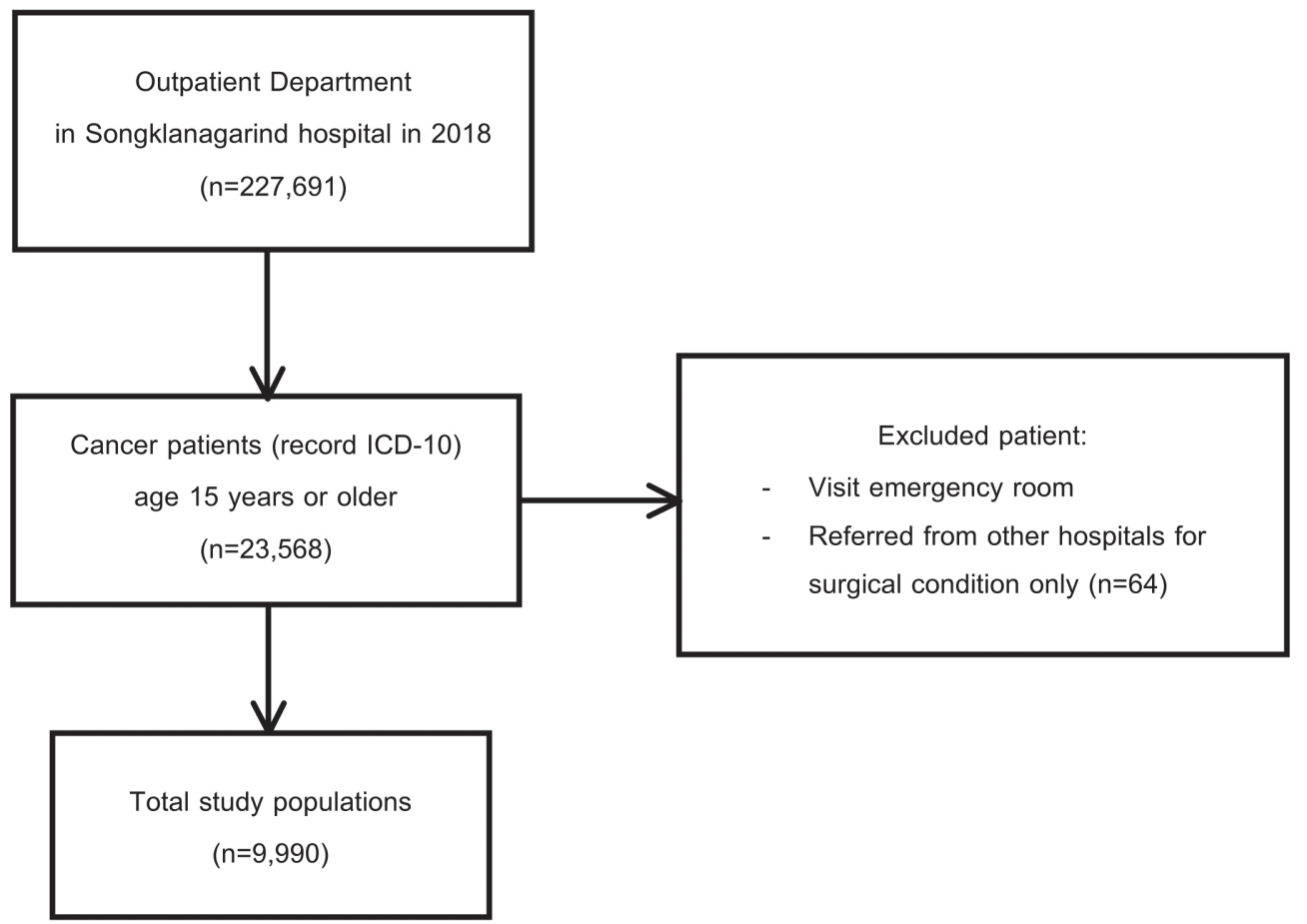

Figure1 Flow chart of patients 
Table 1 Patient characteristics

\begin{tabular}{|c|c|c|}
\hline Characteristic & $\begin{array}{l}\text { Number } \\
(n=9,990)\end{array}$ & $\%$ \\
\hline Age Median (Range) & \multicolumn{2}{|c|}{$58.7(15.1,97.0)$} \\
\hline Missing & 41 & 0.4 \\
\hline \multicolumn{3}{|l|}{ Gender } \\
\hline Female & 6,324 & 63.3 \\
\hline Male & 3,628 & 36.3 \\
\hline Missing & 38 & 0.4 \\
\hline \multicolumn{3}{|l|}{ Health insurance } \\
\hline Universal government insurance coverage for Songklanagarind Hospital & 10 & 0.1 \\
\hline Civil servant medical benefits scheme/State enterprise & 3,156 & 31.6 \\
\hline Cash & 52 & 0.5 \\
\hline Social security system (Referred) & 5 & 0.1 \\
\hline Universal coverage card (Referred) & 95 & 1.0 \\
\hline Local government & 300 & 3.0 \\
\hline Missing & 6,372 & 63.8 \\
\hline \multicolumn{3}{|l|}{ Religion } \\
\hline Buddhist & 8420 & 84.3 \\
\hline Christian & 29 & 0.3 \\
\hline Muslim & 1498 & 15.0 \\
\hline Other & 5 & 0.1 \\
\hline Missing & 38 & 0.4 \\
\hline \multicolumn{3}{|l|}{ Primary cancer site (ICD-10) } \\
\hline C00-14 malignant neoplasms of lip, oral cavity and pharynx & 780 & 7.8 \\
\hline C15-26 malignant neoplasms of digestive organs & 1,755 & 17.6 \\
\hline C30-39 malignant neoplasms of respiratory and intrathoracic organs & 810 & 8.1 \\
\hline C40-41 malignant neoplasms of bone and articular cartilage & 42 & 0.4 \\
\hline C43-44 melanoma and other malignant neoplasms of skin & 172 & 1.7 \\
\hline C45-49 malignant neoplasms of mesothelial and soft tissue & 181 & 1.8 \\
\hline C50-50 malignant neoplasms of breast & 1,887 & 18.9 \\
\hline C51-58 malignant neoplasms of female genital organs & 1,411 & 14.1 \\
\hline C60-63 malignant neoplasms of male genital organs & 331 & 3.3 \\
\hline C64-68 malignant neoplasms of urinary tract & 246 & 2.5 \\
\hline C69-72 malignant neoplasms of eye, brain and other parts of central nervous system & 157 & 1.6 \\
\hline C73-75 malignant neoplasms of thyroid and other endocrine glands & 1,290 & 12.9 \\
\hline C76-80 malignant neoplasms of ill-defined, secondary and unspecified sites & 157 & 1.6 \\
\hline $\begin{array}{l}\text { C } 81-96 \text { malignant neoplasms, stated or presumed to be primary, of lymphoid, haematopoietic and } \\
\text { related tissue }\end{array}$ & 769 & 7.7 \\
\hline C97-97 malignant neoplasms of independent (primary) multiple sites & 2 & 0.0 \\
\hline \multicolumn{3}{|l|}{ Outpatient clinic } \\
\hline Surgery & 3,228 & 32.3 \\
\hline Radiation oncology & 2,233 & 22.4 \\
\hline Medicine & 2,166 & 21.7 \\
\hline Gynecology & 1,261 & 12.6 \\
\hline Ear nose throat & 929 & 9.3 \\
\hline Orthopedics & 50 & 0.5 \\
\hline Ophthalmology & 67 & 0.7 \\
\hline Pediatrics & 46 & 0.5 \\
\hline Skin & 6 & 0.1 \\
\hline Missing & 4 & 0.0 \\
\hline
\end{tabular}

ICD-10=International Classification of Diseases and Related Health Problem $10^{\text {th }}$ Revision 
Table 2 Patients requiring palliative care by characteristics and Supportive and Palliative Care Indicators Tool-Low Income Setting indicators

\begin{tabular}{|c|c|c|c|}
\hline \multirow{2}{*}{ Variable } & \multicolumn{2}{|c|}{ Number (\%) } & \multirow{2}{*}{$\mathrm{P}$-value } \\
\hline & Did not require & Required & \\
\hline Total & 9008 (92.2) & $781(7.8)$ & \\
\hline Age & & & $<0.001^{*}$ \\
\hline Median (Range) & $59.0(15.1,95.8)$ & $63.4(20.3,97.0)$ & \\
\hline Gender & & & $<0.001^{\star *}$ \\
\hline Female & $5,954(64.9)$ & $370(47.5)$ & \\
\hline Male & 3,219 (35.1) & $409(52.5)$ & \\
\hline Religion & & & $0.011^{\$}$ \\
\hline Buddhist & $7,786(84.9)$ & $634(81.4)$ & \\
\hline Christian & $29(0.3)$ & $0(0.0)$ & \\
\hline Muslim & $1,353(14.7)$ & 145 (18.6) & \\
\hline Other & $5(0.1)$ & $0(0.0)$ & \\
\hline Health insurance coverage & & & $<0.001^{\star * *}$ \\
\hline Universal government insurance coverage for Songklanagarind Hospital & $9(0.3)$ & $1(0.4)$ & \\
\hline Civil servant medical benefits scheme (CSMBS)/State enterprise & $2,943(87.7)$ & $213(81.3)$ & \\
\hline Cash & $47(1.4)$ & $5(1.9)$ & \\
\hline Social security system (Referred) & $5(0.1)$ & $0(0.0)$ & \\
\hline Universal coverage card (Referred) & $76(2.3)$ & $19(7.3)$ & \\
\hline Local government & $276(8.2)$ & $24(9.2)$ & \\
\hline Primary cancer site (ICD-10) & & & $<0.001^{\star * *}$ \\
\hline C00-14 malignant neoplasms of lip, oral cavity and pharynx & $697(7.6)$ & $83(10.6)$ & \\
\hline C15-26 malignant neoplasms of digestive organs & $1,522(16.5)$ & $233(29.8)$ & \\
\hline C30-39 malignant neoplasms of respiratory and intrathoracic organs & $673(7.3)$ & $137(17.5)$ & \\
\hline C40-41 malignant neoplasms of bone and articular cartilage & $33(0.4)$ & $9(1.2)$ & \\
\hline C43-44 melanoma and other malignant neoplasms of skin & $164(1.8)$ & $8(1.0)$ & \\
\hline C45-49 malignant neoplasms of mesothelial and soft tissue & $158(1.7)$ & $23(2.9)$ & \\
\hline C50-50 malignant neoplasms of breast & $1,809(19.6)$ & $78(10.0)$ & \\
\hline C51-58 malignant neoplasms of female genital organs & $1,349(14.6)$ & $62(7.9)$ & \\
\hline C60-63 malignant neoplasms of male genital organs & $304(3.3)$ & $27(3.5)$ & \\
\hline C64-68 malignant neoplasms of urinary tract & $225(2.4)$ & $21(2.7)$ & \\
\hline $\begin{array}{l}\text { C69-72 malignant neoplasms of eye, brain and other parts of central } \\
\text { nervous system }\end{array}$ & $144(1.6)$ & $13(1.7)$ & \\
\hline C73-75 malignant neoplasms of thyroid and other endocrine glands & $1,281(13.9)$ & $9(1.2)$ & \\
\hline C76-80 malignant neoplasms of ill-defined, secondary and unspecified sites & $122(1.3)$ & $35(4.5)$ & \\
\hline $\begin{array}{l}\text { C81-96 malignant neoplasms, stated or presumed to be primary, of lymphoid, } \\
\text { haematopoietic and related tissue }\end{array}$ & $726(7.9)$ & $43(5.5)$ & \\
\hline C97-97 malignant neoplasms of independent (primary) multiple sites & $2(0.0)$ & $0(0.0)$ & \\
\hline $\begin{array}{l}\text { SPICT 1: Performance status is poor or deteriorating, best available treatment is } \\
\text { having limited effect (e.g. stays in bed or a chair for more than half the day). }\end{array}$ & & & $<0.001^{* *}$ \\
\hline No & $7,703(83.6)$ & $110(14.1)$ & \\
\hline Not enough data & $1,291(14.0)$ & $28(3.6)$ & \\
\hline Yes & $215(2.3)$ & $643(82.3)$ & \\
\hline $\begin{array}{l}\text { SPICT 2: Depends on others for care due to increasing physical and/or mental } \\
\text { health problems. }\end{array}$ & & & $<0.001^{* *}$ \\
\hline No & $7,600(82.5)$ & $103(13.2)$ & \\
\hline Not enough data & $1,382(15.0)$ & $34(4.4)$ & \\
\hline Yes & $227(2.5)$ & $644(82.5)$ & \\
\hline SPICT 3: The person's caregiver needs more help and support. & & & $<0.001^{* *}$ \\
\hline No & $7,673(83.3)$ & $149(19.1)$ & \\
\hline Not enough data & $1,532(16.6)$ & $626(80.2)$ & \\
\hline Yes & $4(0.0)$ & $6(0.8)$ & \\
\hline
\end{tabular}


Table 2 (continued)

\begin{tabular}{|c|c|c|c|}
\hline \multirow{2}{*}{ Variable } & \multicolumn{2}{|c|}{ Number $(\%)$} & \multirow{2}{*}{ P-value } \\
\hline & Did not require & Required & \\
\hline $\begin{array}{l}\text { SPICT 4: The person has had significant weight loss over the last few months } \\
\text { or remains underweight. }\end{array}$ & & & $<0.001^{* *}$ \\
\hline No & $7,701(83.6)$ & $325(41.6)$ & \\
\hline Not enough data & $1,021(11.1)$ & $175(22.4)$ & \\
\hline Yes & $4,87(5.3)$ & $281(36.0)$ & \\
\hline $\begin{array}{l}\text { SPICT 5: Persistent symptoms despite best available treatment of underlying } \\
\text { condition(s); is unable to access treatment (e.g. due to distance, cost or inability } \\
\text { to travel). }\end{array}$ & & & $<0.001^{* *}$ \\
\hline No & $8,282(89.9)$ & $671(85.9)$ & \\
\hline Not enough data & $892(9.7)$ & $36(4.6)$ & \\
\hline Yes & $35(0.4)$ & $74(9.5)$ & \\
\hline $\begin{array}{l}\text { SPICT 6: The person (or family) asks for palliative care; chooses to reduce, stop } \\
\text { or not have treatment; or wishes to focus on quality of life. }\end{array}$ & & & $<0.001^{* *}$ \\
\hline No & $7,994(86.8)$ & $246(31.5)$ & \\
\hline Not enough data & $1,005(10.9)$ & $30(3.8)$ & \\
\hline Yes & 210 (2.3) & $505(64.7)$ & \\
\hline
\end{tabular}

ICD-10=International Classification of Diseases and Related Health Problem $10^{\text {th }}$ Revision, SPICT $=$ Supportive and Palliative Care Indicators Tool, SPICT-LIS=Supportive and Palliative Care Indicators Tool-Low Income Setting

P-value calculated by *Wilcoxon rank-sum test, ${ }^{* *}$ Chi-squared test, ${ }^{* * *}$ Fisher's exact test

Of the 9,008 patients $(92.2 \%)$ who did not meet the criteria for requiring palliative care, 3,219 were male (35.1\%) and 5,954 were female (64.9\%), with a median age of 59 years. Most of the patients $(87.7 \%)$ were under CSMBS or state enterprise insurance coverage. The top three primary cancers were malignant neoplasms of the breast (19.6\%), malignant neoplasms of the digestive organs (16.5\%) and malignant neoplasms of the female genital organs (14.6\%) (Table 2).

The SPICT-LIS includes 2 general indicators (SPICT 1-2) and 4 clinical indicators (SPICT 3-6) which need to be assessed for cancer patients (Table 2). From the chart reviews, of 781 patients who required palliative care, 643 $(82.3 \%)$ and 644 (82.5\%) met the SPICT 1 and 2 criterions, respectively. $36 \%$ of the patients had had significant weight loss (SPICT 4). Only $9.5 \%$ of the patients had persistent symptoms (SPICT 5). $64.7 \%$ of the patients or their family chose to reduce or stop treatment while focusing on their quality of life (SPICT 6 ). $80.2 \%$ of patients did not have enough information on caregivers (SPICT 3) to assess if they needed help or support (Table 2).

The patients requiring palliative care were significantly older than those who did not $(p-$ value $<0.001)$. More male patients were identified as requiring palliative care than females ( $p$-value<0.001). Religion was associated with patients requiring palliative care $(p-v a l u e=0.011)$. The other potential factors related to requiring palliative care were health insurance plan ( $p$-value<0.001) and primary cancer site ( $p$-value<0.001) (Table 2)

\section{Logistic regression analysis on factors} associated with patients requiring palliative care

The final multivariate model selected by backward stepwise based on best (lowest) AIC using a computerized algorithm with program $\mathrm{R}$ suggested variables including, age, gender, health insurance, religion, and primary cancer 
site. From the final multivariate logistic regression, age was associated with palliative care need $(\mathrm{OR}=1.03,95 \%$ $\mathrm{Cl}=1.02-1.04)$. Muslim patients had a significantly higher requirement for palliative care compared to Buddhist patients (OR=1.62, 95\% Cl=1.09-2.37). Although not statistically significant, malignant neoplasms of bone and articular cartilage showed higher palliative care need than lip, oral cavity and pharynx cancers (OR=5.35, 95\% Cl=0.69-29.40). Patients whose primary cancer was a malignant neoplasm of the skin $(\mathrm{OR}=0.10,95 \% \mathrm{Cl}=0.01-0.53)$, breast $(\mathrm{OR}=0.45$, $95 \% \mathrm{Cl}=0.24-0.87)$ or male genital organs $(\mathrm{OR}=0.45,95 \%$ $\mathrm{Cl}=0.20-0.97$ ) had significantly lower proportions of patients who required palliative care than patients with a malignancy of the lip, oral cavity and/or pharynx (Table 3).

Table 3 Univariate (crude) and multivariate (adjusted) logistic regression of factors associated with patients requiring palliative care

\begin{tabular}{|c|c|c|c|}
\hline Variable & Category & $\begin{array}{l}\text { Univariable } \\
\text { analysis } \\
(95 \% \mathrm{Cl})\end{array}$ & $\begin{array}{l}\text { Multivariable } \\
\text { analysis } \\
(95 \% \mathrm{CI})\end{array}$ \\
\hline Age & & $\begin{array}{l}1.04^{*} \\
(1.02-1.05)\end{array}$ & $\begin{array}{l}1.03^{*} \\
(1.02-1.04)\end{array}$ \\
\hline \multirow[t]{2}{*}{ Gender } & Female & Ref. & Ref. \\
\hline & Male & $\begin{array}{l}1.14 \\
(0.83-1.56)\end{array}$ & $\begin{array}{l}1.09 \\
(0.80-1.50)\end{array}$ \\
\hline \multirow{6}{*}{ Health insurance } & Universal government insurance coverage for Songklanagarind Hospital & Ref. & Ref. \\
\hline & Civil servant medical benefits scheme (CSMBS)/State enterprise & $\begin{array}{l}0.12 \\
(0.01-1.16)\end{array}$ & $\begin{array}{l}0.12 \\
(0.02-2.41)\end{array}$ \\
\hline & Cash & $\begin{array}{l}0.27 \\
(0.02-3.22)\end{array}$ & $\begin{array}{l}0.30 \\
(0.03-6.57)\end{array}$ \\
\hline & Social security system (Referred) & 0.00 & 0.00 \\
\hline & Universal coverage card (Referred) & $\begin{array}{l}0.36 \\
(0.03-3.73)\end{array}$ & $\begin{array}{l}0.51 \\
(0.07-10.42)\end{array}$ \\
\hline & Local government & $\begin{array}{l}0.18 \\
(0.02-1.83)\end{array}$ & $\begin{array}{l}0.17 \\
(0.02-3.40)\end{array}$ \\
\hline \multirow[t]{3}{*}{ Religion } & Buddhist & Ref. & Ref. \\
\hline & Christian & 0.00 & 0.00 \\
\hline & Muslim & $\begin{array}{l}1.53^{*} \\
(1.03-2.27)\end{array}$ & $\begin{array}{l}1.62^{*} \\
(1.09-2.37)\end{array}$ \\
\hline \multirow{9}{*}{$\begin{array}{l}\text { Primary cancer } \\
\text { site (ICD-10) }\end{array}$} & C00-14 malignant neoplasms of lip, oral cavity and pharynx & Ref. & Ref. \\
\hline & C15-26 malignant neoplasms of digestive organs & $\begin{array}{l}1.25 \\
(0.65-2.43)\end{array}$ & $\begin{array}{l}1.24 \\
(0.73-2.22)\end{array}$ \\
\hline & C30-39 malignant neoplasms of respiratory and intrathoracic organs & $\begin{array}{l}0.83 \\
(0.42-1.65)\end{array}$ & $\begin{array}{l}1.29 \\
(0.71-2.44)\end{array}$ \\
\hline & C40-41 malignant neoplasms of bone and articular cartilage & $\begin{array}{l}2.87 \\
(0.41-20.32)\end{array}$ & $\begin{array}{l}5.35 \\
(0.69-29.40)\end{array}$ \\
\hline & C43-44 melanoma and other malignant neoplasms of skin & $\begin{array}{l}0.13 \\
(0.02-1.05)\end{array}$ & $\begin{array}{l}0.10 \\
(0.01-0.53)\end{array}$ \\
\hline & C45-49 malignant neoplasms of mesothelial and soft tissue & $\begin{array}{l}1.07 \\
(0.39-2.99)\end{array}$ & $\begin{array}{l}1.16 \\
(0.43-2.90)\end{array}$ \\
\hline & C50-50 malignant neoplasms of breast & $\begin{array}{l}0.55 \\
(0.26-1.14)\end{array}$ & $\begin{array}{l}0.45 \\
(0.24-0.87)\end{array}$ \\
\hline & C51-58 malignant neoplasms of female genital organs & $\begin{array}{l}1.12 \\
(0.41-3.03)\end{array}$ & $\begin{array}{l}0.61 \\
(0.29-1.27)\end{array}$ \\
\hline & C60-63 malignant neoplasms of male genital organs & $\begin{array}{l}0.55 \\
(0.23-1.31)\end{array}$ & $\begin{array}{l}0.45 \\
(0.20-0.97)\end{array}$ \\
\hline
\end{tabular}


Table 3 (continued)

\begin{tabular}{|c|c|c|c|}
\hline Variable & Category & $\begin{array}{l}\text { Univariable } \\
\text { analysis } \\
(95 \% \mathrm{Cl})\end{array}$ & $\begin{array}{l}\text { Multivariable } \\
\text { analysis } \\
(95 \% \mathrm{Cl})\end{array}$ \\
\hline & C64-68 malignant neoplasms of urinary tract & $\begin{array}{l}1.10 \\
(0.42-2.85)\end{array}$ & $\begin{array}{l}0.74 \\
(0.30-1.72)\end{array}$ \\
\hline & $\begin{array}{l}\text { C69-72 malignant neoplasms of eye, brain and other parts of central } \\
\text { nervous system }\end{array}$ & $\begin{array}{l}1.66 \\
(0.54-5.16)\end{array}$ & $\begin{array}{l}1.97 \\
(0.65-5.34)\end{array}$ \\
\hline & C73-75 malignant neoplasms of thyroid and other endocrine glands & 0.00 & 0.00 \\
\hline & $\begin{array}{l}\text { C76-80 malignant neoplasms of ill-defined, secondary and unspecified } \\
\text { sites }\end{array}$ & $\begin{array}{l}1.63 \\
(0.64-4.16)\end{array}$ & $\begin{array}{l}2.14 \\
(0.87-5.06)\end{array}$ \\
\hline & $\begin{array}{l}\text { C81-96 malignant neoplasms, stated or presumed to be primary, of } \\
\text { lymphoid, haematopoietic and related tissue }\end{array}$ & $\begin{array}{l}0.36 \\
(0.16-0.81)\end{array}$ & $\begin{array}{l}0.66 \\
(0.32-1.35)\end{array}$ \\
\hline & C97-97 malignant neoplasms of independent (primary) multiple sites & 0.00 & 0.00 \\
\hline
\end{tabular}

ICD-10=International Classification of Diseases and Related Health Problem $10^{\text {th }}$ Revision

*indicating statistically significant factors with $p$-value less than 0.050

\section{Discussion}

The overall prevalence of palliative care need by SPICT-LIS in this study was $7.8 \%$, which is less than the study of Hamano ${ }^{13}$ (9.2\%) in 2018, which examined the palliative care need of inpatients over 65 years of age using the SPICT Japanese version at a primary care unit.Cancer patients with intact physical functions might not require palliative care. Our study had a larger sample size and used a new SPICT-LIS questionnaire which was developed from the original SPICT questionnaire to be more suited for the assessment of palliative care-requiring patients in lowincome countries such as Thailand, and collected data from many clinics, so there are differences in context between the studies. In addition, the median age of cancer patients (58.7 years old) in this study was slightly lower.

Our study found that the needs for palliative care in cancer patients increased with age $(\mathrm{OR}=1.02-1.04)$. This finding is not surprising, a study by Teunissen S. and team found that elderly patients with cancer had more symptoms such as depressed mood, urinary tract problems and drowsiness than younger patients so they had a higher need for palliative care than younger patients, especially in terms of symptoms management. ${ }^{16} \mathrm{~A}$ large proportion of elderly people tend to suffer from multiple medical conditions including cardiovascular disease and neurodegenerative disease including cancer ${ }^{17}$, and these age-associated diseases likely impose large burdens which result in decreased quality of life. Therefore, more comorbidities are associated with a higher need for palliative care in elderly patients than younger ones. ${ }^{18}$

Our study found that Muslim patients had significantly higher palliative care needs than Buddhists (OR=1.09-2.37). According to the study of Aasim et al., Muslim patients have many beliefs about health care that lead them to not fully utilize available health care systems. For example, they believe that if they contract a disease or illness, that is their fate and they should not attempt to avoid their fate by seeking medical attention. They also believe that religious activities such as praying or fasting can heal their illnesses, thus leading them to delay seeking allopathic treatment even when they are sick. ${ }^{19}$ So, in terms of palliative care, such delays in seeking treatment will make their status worse 
than other groups of patients when they do finally seek medical care, and the palliative care requirements will also be greater. Further evaluation is needed to understand this association.

Although not statistically significant, malignant neoplasms of bone and articular cartilage showed higher palliative care need than lip, oral cavity and pharynx cancers. In addition, in those patients requiring palliative care, the largest group was those with malignant neoplasms of the bone and articular cartilage. We hypothesize that the reason for this is that the treatment for bone and cartilage cancers has a greater negative effect on the overall health status of these patients than the treatment for other cancers, leading to a higher need for palliative care than other cancer groups. Bone and soft tissue sarcomas are known to have moderate to high risk of developing distant metastases before initiation or during the course of treatment. These aggressive bone and soft tissue sarcomas affect patients physically, psychologically, and spiritually, thus requiring a holistic approach to addressing their needs. ${ }^{20}$ As reported by Ana Martins et al. ${ }^{21}$, patients diagnosed with primary bone cancer in the United Kingdom had a wide range of physical and mental problems arising from their condition.

The results of our study should be interpreted cautiously, taking into account the following limitations. First, some patients might not have been diagnosed with an ICD-10 category related to cancer because of healthcare personnel error and would thus have been excluded from the research. Second, there were some missing data in the hospital information system (HIS) concerning the general indicators of the SPICT-LIS ${ }^{\mathrm{TM}}$ including the primary caregiver and how the patient accessed their healthcare. And there are 2 potential biases in the study. First, there is a potential information bias, as the questionnaire part of the SPICT-LIS ${ }^{\text {TM }}$ was completed by more than one researcher, which could have involved different types of data analyses, and also the medical records in the outpatient departments were recorded by more than one physician which may have led to different data being recorded, and/ or different interpretations of their findings. And second, we would note a possible selection bias, as the research sample group included only patients who came to our tertiary hospital, therefor their diseases may have been more complicated than the diseases seen in primary or secondary hospitals. However, we believe these potential biases would have a minimal effect on this research, as we took careful precautions to mitigate as much as possible these potential biases by clarifying all of the indicators in the SPICT-LIS prior to assigning the researchers their data collection duties.

\section{Conclusion}

Our study found that the prevalence of palliative care needs in cancer patients in the outpatient clinics in Songklanagarind Hospital was high. The most common cancers requiring palliative care were cancers of the digestive organs, respiratory and intrathoracic organs and malignant neoplasms of the lips, oral cavity and pharynx. We conclude that screening with the SPICT-LIS to estimate palliative care needs could be usefully implemented in the internal medicine, surgery and ENT outpatient clinics, and we would also suggest including the orthopedics clinic because of the high need of palliative care revealed by the statistical analysis in various bone cancers, even though the prevalence of these was statistically small.

\section{Acknowledgement}

We would like to thank Dave Patterson for English proof-reading of the manuscript and the $7 \mathrm{~A}$ group of $5^{\text {th }}$ year medical students of year 2019 for data collection. Last but not least we would like to acknowledge the staff of the Medical Data Center for Research and Innovation (MDCRI) of our institution for data curing from the HIS. 


\section{Conflict of interest}

The authors confirm that there are no known conflicts of interest associated with this publication and there has been no significant financial support for this work that could have influenced its outcome.

\section{References}

1. World Population Ageing Report. Aging [homepage on the Internet]. New York: United Nations; 2016 [cited 2020 Jan 24]. Available from: https://www.un.org/en/sections/issues-depth/ ageing

2. World Health Organization Definition of Palliative Care. Cancer [homepage on the Internet]. Geneva: WHO; 2002 [cited 2020 Jan 24]. Available from: https://www.who.int/cancer/palliative/ definition/en/

3. Virani S, Bilheem S, Chansaard W, Chitapanarux I, Daoprasert K, Khuanchana S, et al. National and subnational populationbased incidence of cancer in Thailand: assessing cancers with the highest burdens. Cancers (Basel) 2017;9:8.

4. Cruz-Oliver DM. Palliative care: an update. Mo Med 2017;114 110-5.

5. Division of Non-Communicable Diseases. Number and rate of inpatients from 2016-2018 (hypertension, diabetic mellitus, cardiovascular diseases, chronic obstructive pulmonary disease) [homepage on the Internet]. Bangkok: Division of NonCommunicable Diseases, Thailand; 2018 [cited 2020 Jan 24]. Available from: http://www.thaincd.com/2016/mission/ documents-detail.php?id=13684\&tid=32\&gid=1-020

6. Mcateer R, Wellbery C. Palliative care: benefits, barriers, and best practices [monograph on the Internet]. Washington: American Family Physician; 2015 [cited 2020 Jan 24]. Available from: https://www.aafp.org/afp/2013/1215/p807.html

7. World Health Organization. Palliative care: for all ages and all diseases [homepage on the Internet]. Geneva: WHO; 2015 [cited 2020 Jan 24]. Available from: http://www.who.int/features/ 2015/south-africa-palliative-care/en/

8. Smith T, Coyne P, Cassel J. Practical guidelines for developing new palliative care services: resource management. Ann Oncol 2012;23:70-5.

9. World Health Organization. Noncommunicable diseases and their risk factors: palliative care [homepage on the Internet].
Geneva: WHO; 2019 [cited 2020 Jan 24]. Available from: https://www.who.int/ncds/management/palliative-care/en/

10. Supportive and Palliative Care Indicators Tool. SPICT-LISTM [homepage on the Internet]. Edinburgh: The University of Edinburgh; 2019 [cited 2020 Apr 24]. Available from: https:// www.spict.org.uk/the-spict/spict-lis/

11. Glare P, Semple D, Stabler S, Saltz L. Palliative care in the outpatient oncology setting: evaluation of a practical set of referral criteria. J Oncol Pract 2011;7:366-70.

12. Stubbs JM, Assareh H, Achat HM, Greenaway S, Muruganantham P. Specialist palliative care activity at an acute care tertiary hospital and its representation in administrative data. Am J Hosp Palliat Care 2020. doi: 10.1177/1049909120939861.

13. Hamano J, Oishi A, Kizawa Y. Identified palliative care approach needs with SPICT in family practice: a preliminary observational study. J Palliat Med 2018;21:992-8.

14. Highet G, Crawford D, Murray S, Boyd K. Development and evaluation of the supportive and palliative care indicators tool (SPICT): a mixed-methods study. BMJ Support Palliat Care 2014;4:285-90.

15. Bock R, Noortgate N, Piers R. Validation of the supportive and palliative care indicators tool in a geriatric population. J Palliat Med 2018;21:220-4

16. Teunissen S, Haes H, Voest E, Graeff A. Does age matter in palliative care? Crit Rev Oncol Hematol 2006;60:152-8.

17. World Health Organization. Palliative care for older people: better practices [homepage on the Internet]. Geneva: WHO; 2011 [cited 2020 Jan 24]. Available from: http://www.euro.who. int/

18. Europe World Health Organization. What are the palliative care needs of older people and how might they be met? [homepage on the Internet]. Denmark: WHO; 2004 [cited 2020 Jan 24]. Available from: http://www.euro.who.int/_data/

19. Padela A, Zaidi D. The Islamic tradition and health inequities: A preliminary conceptual model based on a systematic literature review of Muslim health-care disparities. Avicenna J Med 2018; 8:1-13.

20. Gulia A, Byregowda S, Panda P. Palliative care in musculoskeletal oncology. Indian J Palliat Care 2016;22:244-51.

21. Martins A, Whelan J, Bennister LA, Fern L, Gerrand C, Onasanya $M$, et al. Qualitative study exploring patients experiences of being diagnosed and living with primary bone cancer in the UK. BMJ Open 2019;24:9. 